\title{
Social Exclusion and School Achievement: Children of Immigrants and Children of Natives in Three European Countries
}

\author{
Isabel J. Raabe ${ }^{1,2}$ (D)
}

Accepted: 30 May 2018 / Published online: 18 June 2018

(C) The Author(s) 2018

\begin{abstract}
Ethnic minorities in Europe show diverging patterns of educational success, but in most national contexts, migrants and children of immigrants have lower achievements in terms of grades than their majority peers. This study asks whether social exclusion in the classroom can contribute to explaining this pattern. While limited access to social resources is often assumed to be of significance for educational success, it has rarely been measured explicitly. In this study, social exclusion is measured accurately and on a large, cross-national scale, by using social network data from 731 classrooms in England, Germany, and Sweden (CILS4EU data). Results show that social exclusion is negatively associated with school grades, but this does not contribute much to understanding grade differences between children of immigrant and children of majority background.
\end{abstract}

Keywords Educational inequality $\cdot$ Social exclusion $\cdot$ Immigrants

\section{Introduction}

Social resources are crucial for educational success: Social exclusion in the classroom can severely compromise access to those resources, which can have detrimental effects on educational success and thus, in the long run, socioeconomic attainment. This

Electronic supplementary material The online version of this article (https://doi.org/10.1007/s12187-0189565-0) contains supplementary material, which is available to authorized users.

Isabel J. Raabe

isabel.raabe@nuffield.ox.ac.uk

1 Department of Sociology, Nuffield College, University of Oxford, New Road, OX1 1NF Oxford, Oxfordshire, UK

2 Chair of Social Networks, ETH Zürich, Weinbergstrasse 109, 8092 Zürich, Switzerland 
applies in particular to groups that are vulnerable to begin with, such as children of immigrants. Strategic knowledge about the education system, about manners, values and cultural codes that prevail at school, and access to networks of support and inspiration that promote learning and performance are typically less available to children of immigrants ${ }^{1}$ than to their ethnic majority peers. Their parents, migrants themselves, are more likely to lack these types of resources, rendering the existence and quality of social relations and connections at school more critical and decisive for their educational career. If ethnic minority children are able to establish a network of support and resources for themselves within school, this can counteract those disadvantages. However, if ethnic minority children are socially isolated and avoided, these types of support networks are less likely to be established. This inequality of network resources then contributes to the perpetuation of already existing ethnic stratification patterns. Thus, the main question that this paper seeks to answer is: Can social exclusion help explain ethnic differences in school achievement?

While it is not a new idea to consider social network resources (especially Lin 1999, 2000), the fact that social exclusion is difficult to measure adequately on a large-scale basis has resulted in a scarcity of empirical research on its consequences. Through the utilisation of social network data, this paper adequately measures social exclusion in the form of social isolation (absence of friendship) and social avoidance (negative relationships). Using the CILS4EU data (Children of Immigrants Longitudinal Survey in Four European Countries), the analysis is furthermore able to test this dynamic in several national contexts. This study uses sociometric data, i.e. social network data, on 15,017 students in 731 classrooms in England, Germany, and Sweden. These countries differ in their institutional arrangements and in patterns of ethnic educational stratification, and this variation in contexts is particularly valuable for testing the occurrence of general mechanisms. The high number of networks and the possibility of generalising the results to populations in several countries are exceptional due to high costs and effort associated to the collection of social network data.

\section{The Social Dimension of Educational Success}

Research in social stratification has long focused on diverging educational success, both attainment and performance, with the traditional predictor being the socioeconomic background of the family. Following increased immigration rates in many Western societies, recent research has increasingly considered ethnic inequalities in educational success (e.g. Heath et al. 2008). While research on first generation immigrants has singled out language skills and pre-migration educational qualifications as obstacles to achieving higher education (van Tubergen and van de Werfhorst 2007), a lot of recent research on ethnic inequalities has focused on the second generation, that is, children born in host countries to immigrant parents, where other explanations need to be sought. These results show that the socioeconomic origin of immigrant groups is

\footnotetext{
${ }^{1}$ In this paper, the term "ethnic minority children is used to refer to children of immigrants. While in many European countries there are also ethnic minority individuals that are not of immigrant origin, this applied to the majority of ethnic minority individuals in Europe. Nevertheless, this equivalence does not apply in all cases.
} 
behind much, but not all, of the overall poorer performance of ethnic minority groups (Heath and Brinbaum 2014). A potential explanation for the remaining minority disadvantage is the social dimension of youths, as expressed in their social networks, friendship patterns, and social exclusion such as bullying and social isolation. Such a focus acknowledges that the role of peers becomes more significant during adolescence (Osterman 2000; Youniss and Smollar 1985). Since adolescents spend the majority of their time at school, the school class is a particularly significant social context for them, and as a societal 'micro-system' the school class harbours both positive and negative peer relations. The aim of this paper is to analyse whether negative relations may lead to disadvantage in school achievement, and whether this more severe to the ethnic minority group.

\section{Social Exclusion and Limited Access to Social Network Resources}

When it comes to negative social relations at school, most research has focused on bullying and its negative effects on a variety of outcomes (e.g. McDougall and Vaillancourt 2015), however, subtler forms of negative relationships are likely to play a role, too. In particular, isolation, i.e. having no friends, and being avoided by others are forms of a non-positive social environment in the class, which have not been researched as extensively as bullying. Both forms are less explicit than bullying, but can nevertheless be detrimental when it comes to individual outcomes, including educational success.

There are some factors suggesting that ethnic minorities are at a higher risk of being socially excluded. Social misfit theory proposes that individuals are avoided when they are different in one or several regards (Wright et al. 1986), which could be the ethnic or cultural background. Furthermore, recent studies find that youths with a migration background in Sweden are not only more likely to be victimised (e.g. Vervoort et al. 2008), but are also at a higher risk to face subtler forms of exclusion (Plenty and Jonsson 2017). Work on friendships and friendship networks, has shown repeatedly that friendship is more likely and more stable between individuals that are similar to each other, a phenomenon known as homophily (McPherson et al. 2001). This applies in particular to ethnic background (Boda and Néray 2015). Thus, depending on the ethnic composition in the classroom, ethnic minorities can be at a higher risk of not being able to form or initiate stable friendships if there is not much opportunity of befriending someone with a similar ethnic background.

While the need to belong is a fundamental human need that applies to people of all ages (Baumeister and Leary 1995), it has been found that belonging and social acceptance is particularly important for adolescents' well-being (Brown 2004), relative to adults or children. Previous research has documented the negative effects of low mental well-being on educational outcomes (Nakamoto and Schwartz 2010), but there can also be direct effects from being isolated and avoided on academic achievement, since social exclusion will reduce the chance of learning from others, doing homework together, or drawing on friends' parents for academic support, such as strategic knowledge on how to navigate the education system (Erikson and Jonsson 1996). These social network resources can be conceptualised as quantity and quality of resources that an actor can access through their location in a social network, i.e. through 
the people he or she knows, and who these people know (Lin 2000). Network structures themselves can also lead to more stable beneficial connections, e.g. through being embedded in close friendship groups (Block 2015). These types of resources have been found to mediate part of the effect of social origin on educational and occupational attainment (e.g. Jencks et al. 1983), and may counterbalance disadvantages created by lower parental socioeconomic resources. However, access to beneficial social resources is often also compromised by initial inequality, which can aggravate these already existing inequalities. Since personal networks tend to be segregated along a variety of personal characteristics, such as gender and age, but also socioeconomic status (McPherson et al. 2001), there is an increased risk for initial inequalities to be reinforced: Those who are already at an advantageous position will be able to promote this more due to access to the social resources that this network position carries, and those who are already disadvantaged cannot exploit their social contacts to the same extent, and are left behind even more (Lin 2000).

\section{Isolation and Avoidance in the Classroom}

Classrooms, in which children and adolescents spend a lot of time, provide a potential opportunity for gaining access to social network resources. Although classrooms tend to be sorted by ability and parental background, due to residential segregation or in some countries due to a tracked education system, they are still an important environment for associating with others in the same life situation but with a potentially different background: ethnic as well as socioeconomic. Therefore, school classes have the potential to provide a platform for the access of valuable social network resources, but social exclusion can inhibit the access to such resources.

There are several different ways in which pupils can be socially excluded, such as isolation and avoidance. Isolation here is understood as the absence of personal links (e.g. friendship ties), and can either be understood with reference to everyone in the classroom (complete isolation), or just with reference to the majority students in the classroom (isolation from majority students). Avoidance implies negative relations, such as dislike.

Social resources of students in classrooms in which they are isolated and/or avoided are compromised. This applies in particular to complete isolation, and high levels of general avoidance: isolation from or avoidance by natives can be counteracted by resources provided by ethnic minorities. Distinguishing between these cases, however, goes beyond the scope of this paper; this is further elaborated on in the discussion. Drawing on the arguments above, the first hypothesis on social exclusion thus states:

\section{Hypothesis 1: Social exclusion has a negative effect on educational performance.}

While ethnic minority pupils are expected to be more socially excluded, it is furthermore assumed that this varies with respect to the generational status, i.e. how long individuals' families have been in the host country. Especially newly arrived migrants, i.e. those that have only been in the country for a couple of years, are at a higher risk of being socially excluded, for example due to language barriers or simply because they have had a shorter time to make friends. The second generation, who were 
born in the host country, will less frequently face such problems, but may still not be fully integrated socially due to homophily tendencies as well as prejudice. In combination with hypothesis one, it is thus hypothesised:

Hypothesis 2: Social exclusion explains immigrant disadvantages in educational success.

Hypothesis 3: This tendency is expected to be strongest for newly arrived immigrants.

Furthermore, social exclusion may have more detrimental consequences for school achievement for children of immigrant origin than for those with native-born parents. This is because the latter have gone through the host-country educational system themselves, and can thus offer better advice than parents who have never attended school in the destination country. In addition to this practical help, language barriers could render it more difficult for parents of students with a migration background to seek information on opportunities and support that might be available. Thus, children of immigrant origin are likely to be in more need of social resources outside the family. Consequently, the fourth hypothesis states:

\section{Hypothesis 4: The negative association between social exclusion and educational performance is stronger for students with a migration background.}

With the utilisation of social network data to measure social exclusion on a large scale, this analysis manages to explicitly test a mechanism that has received a lot of attention in theoretical works, but which has not received much empirical attention, due to lack of suitable data.

\section{Data and Methods}

\subsection{Data}

The data analysed in this paper is from the first two waves of the Children of Immigrants Longitudinal Survey in Four European Countries (CILS4EU) data-set, which focuses on the integration of first and second generation youths in four European countries: England, Sweden, Germany, and the Netherlands (Kalter et al. 2014, 2015). This is the first comprehensive dataset that is fully standardised, longitudinal, and generalisable to the survey country populations, providing data on youths, teachers, and parents, as well as information on class-room social networks. Wave 1 of this survey interviewed students at age 14-15, and wave 2 at age 15-16. The survey includes information on minority and majority ethnic groups, oversampling immigrant-dense schools in order to increase power in the analyses that focus on ethnic minority students.

This study uses data from England, Germany, and Sweden. Since the education system in the Netherlands is not strictly classroom-based to the same extent as in the other countries, the measure of social exclusion through the classroom-networks is regarded to be less valid than in the other countries; thus, this country is excluded from 
the analysis. In total, the sample used here has information on 15,017 students in 731 classrooms, in 381 schools. Mostly, two classrooms per school were included in the sample, with an average of 20.6 students in each classroom.

\subsection{Variables}

Descriptives of all variables used are reported in Table 1, in the full data set and in the analytical sample, respectively. Around one third of all respondents had missing information on one or more variables that were included in the analysis, mainly due to missingness on the outcome variable, grade point average (GPA; 3328 of 15,017 cases). When comparing the variable distributions of the original sample to the analytical sample, that is the sample of all complete cases, there are no substantial differences between the two samples, therefore it is assumed that there is no systematic attrition that results from list-wise deletion.

The outcome variable GPA was collected in wave 2, while the predictor variables are taken from wave 1.

\subsubsection{Outcome Variable: Grade Point Average (GPA)}

The outcome is GPA, measured as the average of the school grades in mathematics and the survey country language. This is available as self-reported grades for England and Germany, and as teacher-assigned grades taken from school-register data for Sweden. This renders the data for Sweden more objective, and presumably of higher quality. The measure for GPA is z-standardised within each country, because countries use different grading scales. For interpretation, this means that a unit change in the outcome variable refers to a change in the distribution of grades, expressed in standard deviations.

\subsubsection{Main Predictor 1: Migration Background as Generational Status}

Migration background is included in the models as a categorical variable, based on the official generation status variable available in the CILS4EU data-set, constructed according to the "ancestral distance" of the respondents to their immigrating ancestors (Dollmann et al. 2014). The official variable was constructed using information on country of origin and age of arrival in the survey country of the child, his or her parents as well as grandparents. Based on this, the variable takes four values for the purpose of this analysis.

First, "majority" refers to adolescents whose parents were born in the survey country. Second, "newly arrived" captures those that arrived after the age of 10, who have been in the country for only a few years: at the point of time of the survey, youths were mostly between 14 and 15 years old. Third, the "first generation", i.e. those who migrated themselves, but arrived before the age of 10. Fourth, the "second generation" refers to those who were born in the survey country, but whose parents have been born abroad.

Since the main analysis here pools data from the three countries, differentiating between countries or regions of origin is not feasible, as the survey countries vary substantially in the ethnic composition of their immigrant populations; this would have led to a low number of cases in some categories. Thus, this paper utilises the 


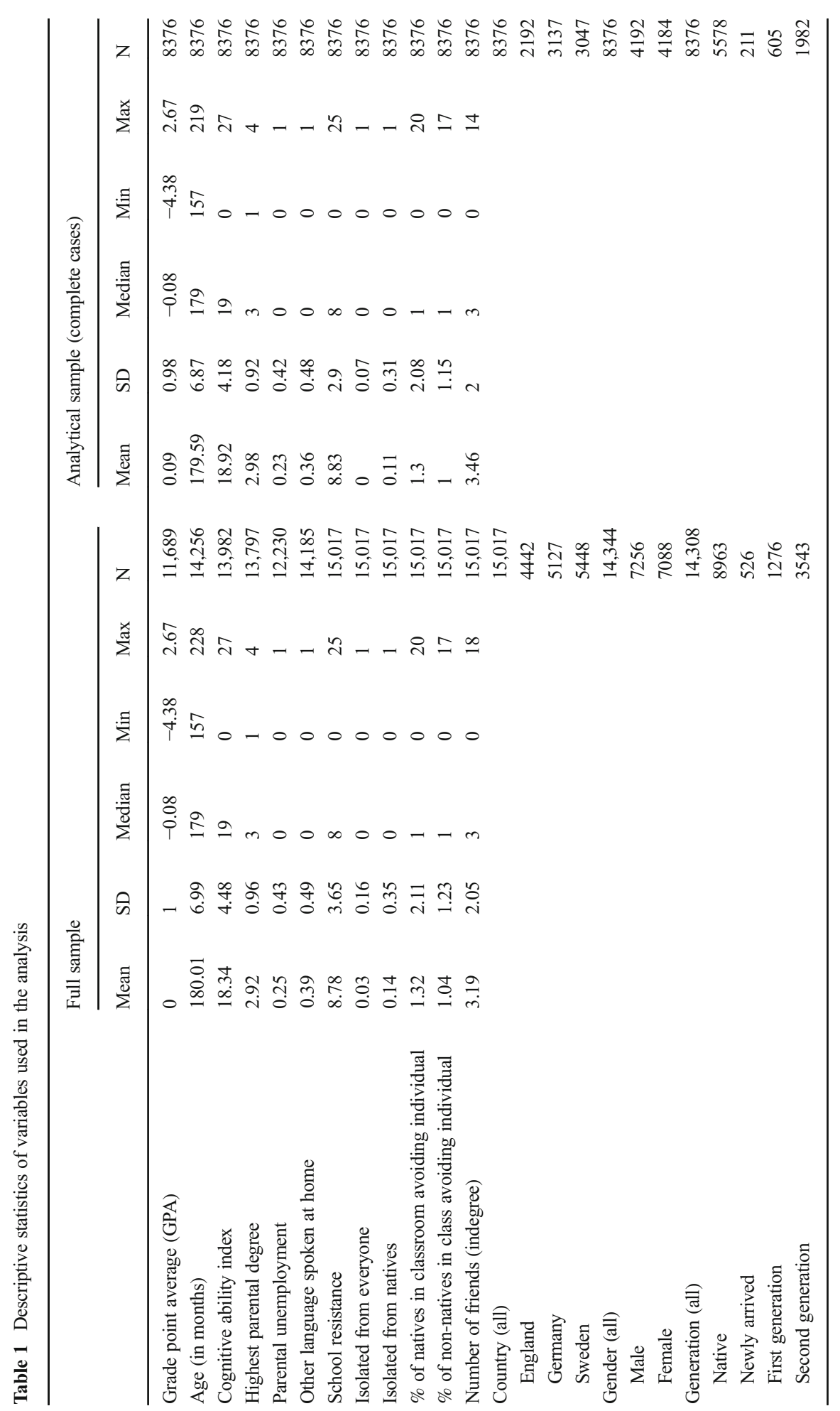


generation status in the main analysis, and uses the ethnic composition of the immigration population in the country-specific interpretation of the results. The ethnic composition of the generational status categories of the pooled data is presented in Table A2 in the appendix. Additionally, country-specific analyses are included in Tables A3 to A8 in the appendix.

\subsubsection{Main Predictor 2: Social Exclusion}

In line which what has been discussed in the literature review, social exclusion is conceptualised here both as social isolation and social avoidance, by accounting more closely for the type of isolation, as well as for the migration background of those who avoid the individual. It has been shown that different types of relations between individuals, such as absence of friendship and avoidance are best considered jointly to measure a complex social situation, such as exclusion (Vörös and Snijders 2017).

1) Isolation from everyone in the class. This dichotomised variable captures social isolation as the complete absence of friendship nominations by classmates. $3.6 \%$ of majority students and $3.8 \%$ of minority students are isolated from everyone in the class.

2) Isolation from majority students in the class. This dichotomised variable accounts for individuals not receiving friendship nominations from majority students in the classroom, but from minority students. They are thus not isolated completely, as in (1), but they are isolated from the majority students in the class. $3.5 \%$ of majority students and $31.1 \%$ of minority students are isolated from majority students in the class, and have no majority friends outside the classroom, either.

3) Avoidance by majority students in the class. This variable captures the number of incoming avoidance ties from majority students in the classroom, and expresses this as a proportion of all majority students in the classroom. The avoidance tie is based on the survey question "who do you not want to sit next to?". A value of 0.5 would thus mean that $50 \%$ of majority students in the classroom report that they do not want to sit next to the individual.

4) Avoidance by minority students in the class. Following the same logic as in (3), this variable measures avoidance by minority-students in the classroom.

For measures 3 and 4, avoidance ties from those that the individual considers to be their friend are not counted. Among friends, there can be various reasons of why they do not want to sit together, such as being able to better concentrate on the lessons. Approximately $6 \%$ of 37,532 recorded avoidance ties (across all three countries) were dropped based on this reasoning. Additionally, the analyses were carried out without dropping those ties. The results suggest that the measure of social avoidance is more accurately tapping into the dimension of interest here if the ties from friends are dropped (more details are provided in the section on robustness checks).

Figures 1 and 2 show how the measures for avoidance and isolation apply by migration background. These descriptives show two main aspects. First, minority students are a lot more likely to be isolated from majority students than majority students themselves are; this applies in particular to newly arrived immigrants. Second, avoidance ties seem to exist more within groups, i.e. majority and minority, than 
Isolation by migration background

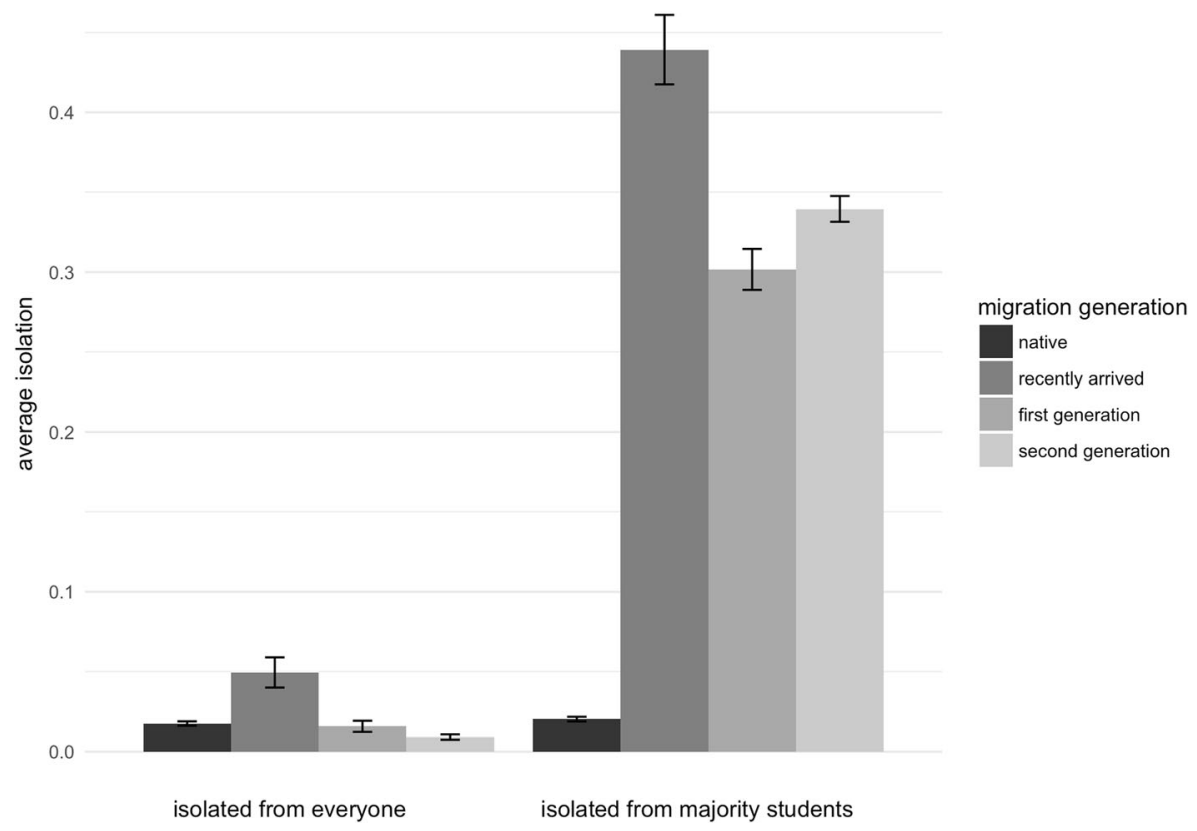

Fig. 1 Extent of avoidance (isolation) of students of different migration background

\section{Avoidance by migration background}

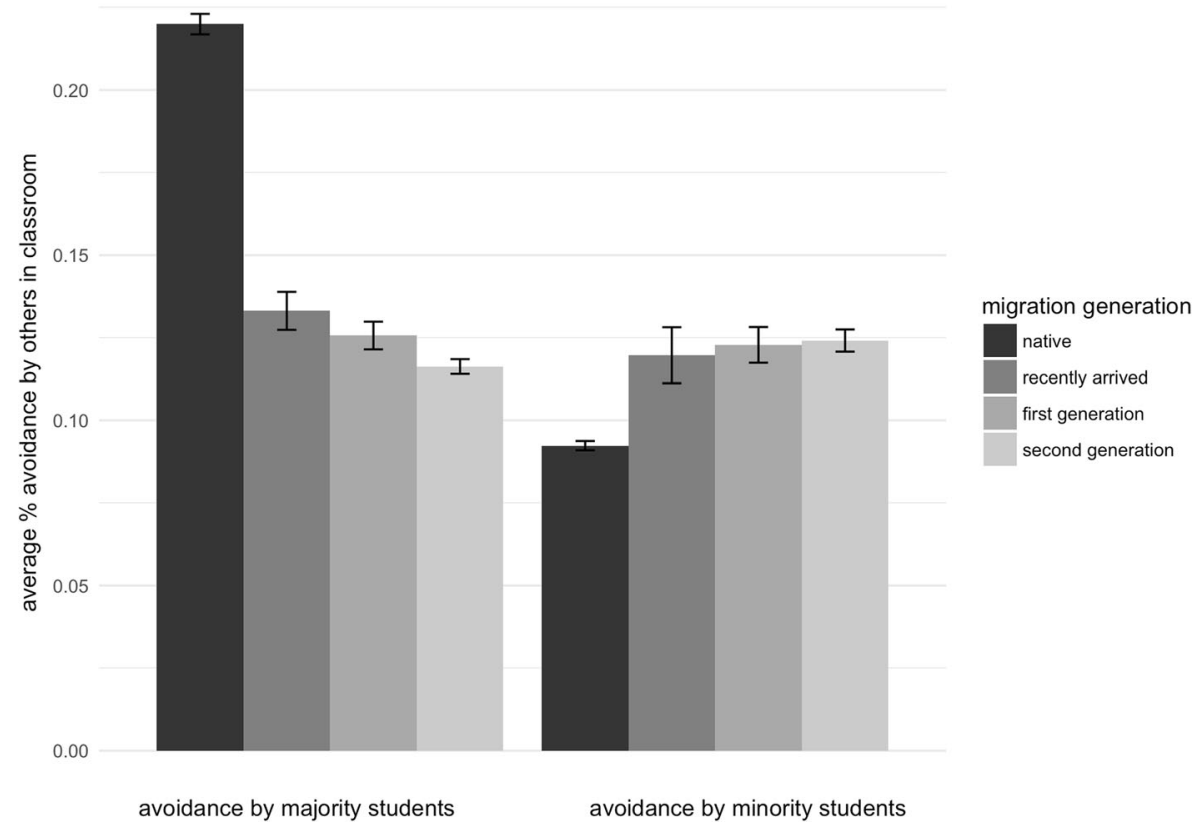

Fig. 2 Extent of social exclusion (avoidance) of students of different migration background 
between groups. Newly arrived minority students are more often than other minority students avoided by majority students. This supports the above-discussed tendency of newly arrived immigrants being particularly vulnerable to social exclusion, especially to social exclusion from majority students.

\subsubsection{Controls}

The analysis furthermore controls for a variety of individual characteristics which are likely to affect grade point average, too. Besides gender and age (in months at the survey date), the models include a measure of cognitive ability. This is the result of a language-free test that is part of the CILS4EU data, and which is based on solving graphical problems in a given time (CILS4EU 2014). This is included in the model to control for baseline differences in ability. Predicting grades controlling for cognitive ability accounts for the individual's potential to get high grades at school, which is an important, but not perfect predictor.

To account for baseline differences in language ability, which is crucial to include when considering ethnic differences, a dummy of whether another language, besides the survey country language, is spoken at home. This is preferred to a language ability test, which is included in the data as well, because of potential endogeneity in this test variable (those of immigrant origin probably improve their language proficiency if they have majority friends). Additionally, the language test result is highly correlated with the cognitive ability index.

Parental background is controlled for by the highest level of parental educational attainment, which includes four categories: primary school, lower secondary school, higher secondary school, and university degree. A control for parental unemployment is included in the models as well, since past research has shown that youths with fewer economic resources are more likely to be excluded from activities and friendships (Hjalmarsson and Mood 2015). The unemployment variable is a dummy, accounting for whether there is not at least one parent living with the adolescents who is employed.

Resistance to schooling is controlled for, too, as it is an important alternative explanation for low grades. Following Geven et al. (2017), a measure for resistance to schooling is computed based on five survey items that capture the extent of the individual (1) arguing with teachers, (2) getting punishments at school, (3) skipping classes, (4) being late to classes, and (5) putting effort into work for school. These items load on one factor with individual loadings between 0.4 and 0.8 (Crohnbach's alpha= 0.71). The items were combined additively, with the fifth item being reversed; noncomplete cases on all five items were assigned a missing value on the scale.

Furthermore, the models control for number of friends, measured as the in-degree, i.e. the number of people who nominate the individual as a friend. This control is included here since the aim of the analysis is to understand the effect of other types of social exclusion besides the effect of absence of friends. Three of the four measures used in this analysis do not exclude the possibility of having friends. Those who are considered to be isolated from majority students only, have friends who do not belong to the majority group. The two measures of avoidance do not consider friends at all, and only account for avoidance relationships. The effect of isolation from majority students or avoidance net of number of friends can show if it is the exclusion from a certain sub- 
group of people in the classroom that makes a difference, rather than being completely excluded from everyone.

Official survey weights were used in all models to account for the over-sampling of immigrant-dense classrooms.

\subsection{Methods}

Linear regression models with standard errors clustered at classroom level are utilised to predict the grade point average (GPA) from CILS4EU wave 2; predictors are from wave 1 , with approximately one year between the two waves. After confirming that there is no country-heterogeneity in the social exclusion effects, which was tested by including country interactions (see Table A2 in the Appendix), analyses were run on pooled data from the three countries. Additionally, all models were run separately for each country (see models A3 to A8 in the Appendix): where country-specific differences are found, they are discussed in the results section. In the first set of models, Model 1 predicts GPA only by migration background. In the next step, the controls described above are added (Model 2), then measures of social exclusion (Model 3). In the second set of models, interaction effects between migration background and all social exclusion variables are added to the full model configuration. This is done with a dummy of migration background (native, i.e. belonging to the majority, vs. first or second generation) and separately for each measure of social exclusion.

All analyses have been carried out in $\mathrm{R}$, version 3.2.2, using the plm package for the regression analysis, and the computation of clustered standard errors. Clustered standard errors are calculated according to Stock and Watson (2008), which is the standard procedure in many statistical packages, such as Stata.

\section{Results}

\subsection{Descriptive Results}

Before the results of the step-wise regression analyses are discussed, the relationship of interest here, i.e. between social exclusion and GPA, is explored descriptively.

Figure 3 shows the relationship between GPA and being socially isolated from everyone, and from majority students, respectively. Figure 4 shows the relationship between GPA and being avoided by majority students, and by ethnic minority students, respectively. For the purpose of this graph, an individual was considered to be socially avoided when at least $30 \%$ of majority children in the classroom (or ethnic minority students, respectively) reported that they avoid the individual - this was considered to be a high enough, yet still somewhat conservative, threshold. All associations between the social exclusion measures and GPA are presented separately for majority students and ethnic minority students.

When comparing the type of social exclusion, i.e. isolation (Fig. 3) and avoidance (Fig. 4), there are some similar patterns, and some differences. First, socially excluded pupils (either of minority or majority origin) get lower grades than non-excluded students. Second, non-excluded majority children get the highest grades, while excluded ethnic minority students receive the lowest grades, 
Isolation from everyone

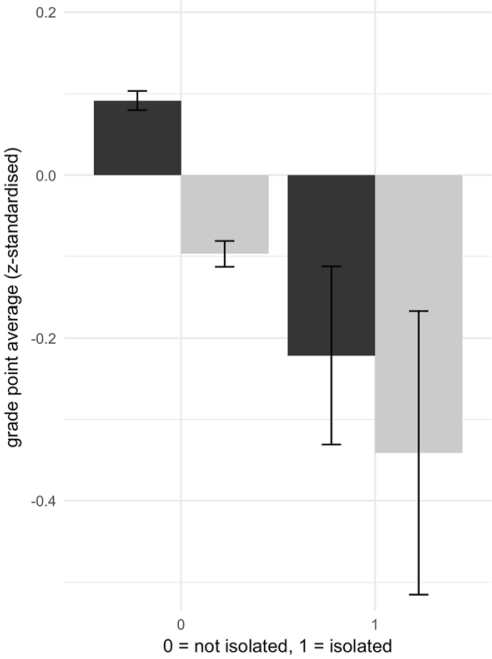

Isolation from majority students

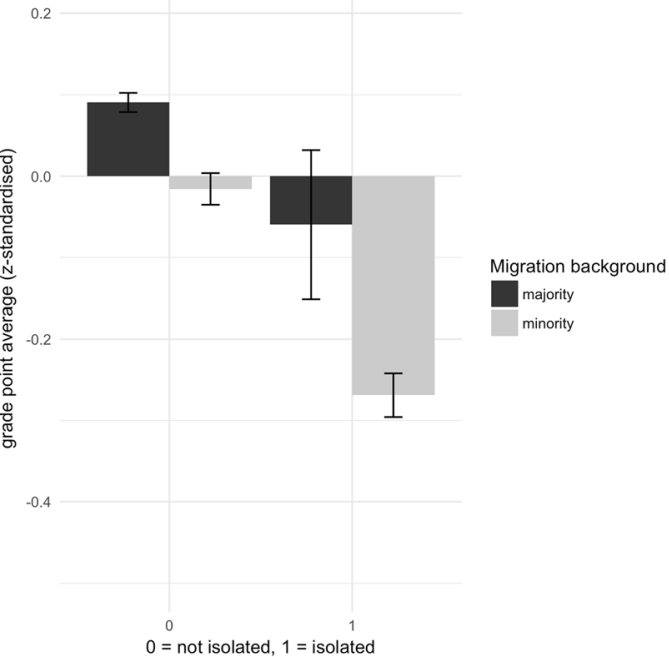

Fig. 3 Grade point average by extent of social exclusion (isolation) and migration background

in all four cases. There are, however, also some differences between isolation and avoidance. First, majority children who are isolated from everyone tend to get significantly lower grades than those who are avoided. Second, ethnic minority students who are avoided by majority students tend to get significantly lower grades than those who are isolated.

These descriptive results point to the existence of the relationship hypothesised in this paper, i.e. a negative association between grades and being socially excluded, as well as to a tendency for ethnic minority students to be more vulnerable when they are excluded.

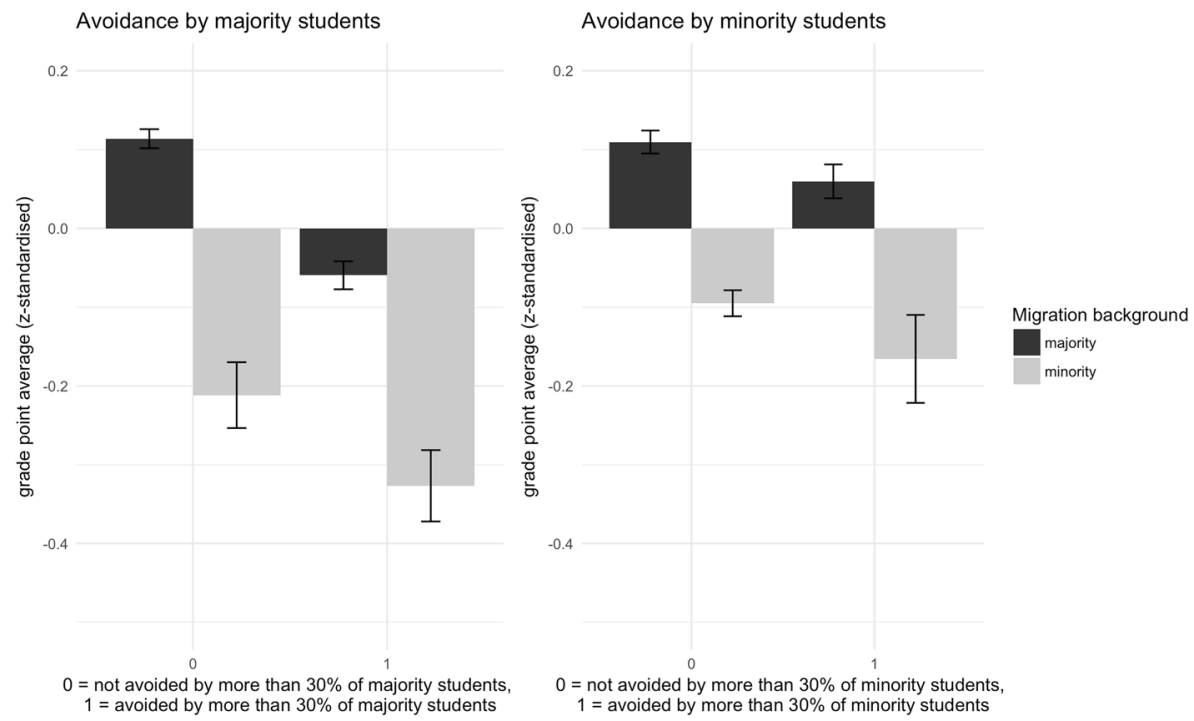

Fig. 4 Grade point average by extent of social exclusion (avoidance) and migration background 


\subsection{Results from Regression Analyses}

Hypothesis 1, stating that social exclusion has a negative effect on educational performance, is supported by the analyses in Table 2. Of the four exclusion measures, two have a significantly negative effect on grade point average: Being isolated from majority students and being socially avoided by majority students in the classroom. This applies while controlling for ethnic background, socio-demographic, cognitive and personality-related factors. Notably, this also applies when controlling for the number of in-going friendship nominations, i.e. the number of people reporting that they are friends with the individual. This points to the fact that social avoidance, especially by majority students, has a negative effect, even if the individual has other friends in the classroom. The net effects, however, are relatively weak: Being isolated from majority students is associated with a 0.09 standard deviation's reduction in grades across our three countries, and a similar reduction in avoidance by majority students by 25 percentage points is related to a similar grade reduction $(0.39 / 4=0.10)$.

While the direction of the effect is the same in all three countries, there are some differences in effect sizes and significance levels (see Tables A3 to A5 in the Appendix): in England, the results are weakest, with non-significant but substantial effect sizes in the same direction, and in Germany strongest, with substantial and significant negative effects for social isolation from majority students and social avoidance by majority students. Sweden is in the middle range, with only avoidance by majority students having a negative effect.

Hypothesis 2 states that the negative effect of social exclusion accounting for immigrant disadvantages in educational success. This hypothesis is only partly supported (see Table 2). After including individual and parental controls (Model 2), the results show ethnic penalties for the first generation overall (though stronger for those who arrived at an older age), but not for the second, i.e. those born in the host country to immigrated parents. Where penalties are found, they decrease when controlling for social exclusion, but only marginally (and the reductions are not statistically significant). As the same general pattern shows for each survey country, the interpretation that social exclusion is behind some of the achievement differences is strengthened.

Hypothesis 3 states that the tendency of social exclusion accounting for immigrant disadvantages is strongest for those who migrated themselves. This is partly supported (see Table 2). In the model on the pooled data, social exclusion has most explanatory power when it comes to disadvantages of newly arrived immigrants. The countryspecific models show the same tendency for England and Sweden, but in Germany, this also applies to second generation Turkish youths.

Hypothesis 4, stating that the negative effect of social exclusion on educational performance is worse for students with a migration background, is not supported (see Table 3). The interaction effects show that, while including all controls mentioned as well as the other forms of exclusion, three measures of social exclusion have negative effect sizes, but none of the four is statistically significant.

When considering how these findings vary by survey country (see Tables A6 to A8 in the appendix), very similar results are observed: None of the interaction effects suggests that a particular exclusion measure is significantly worse for migrants than it is for majority students. For Germany, however, the results 


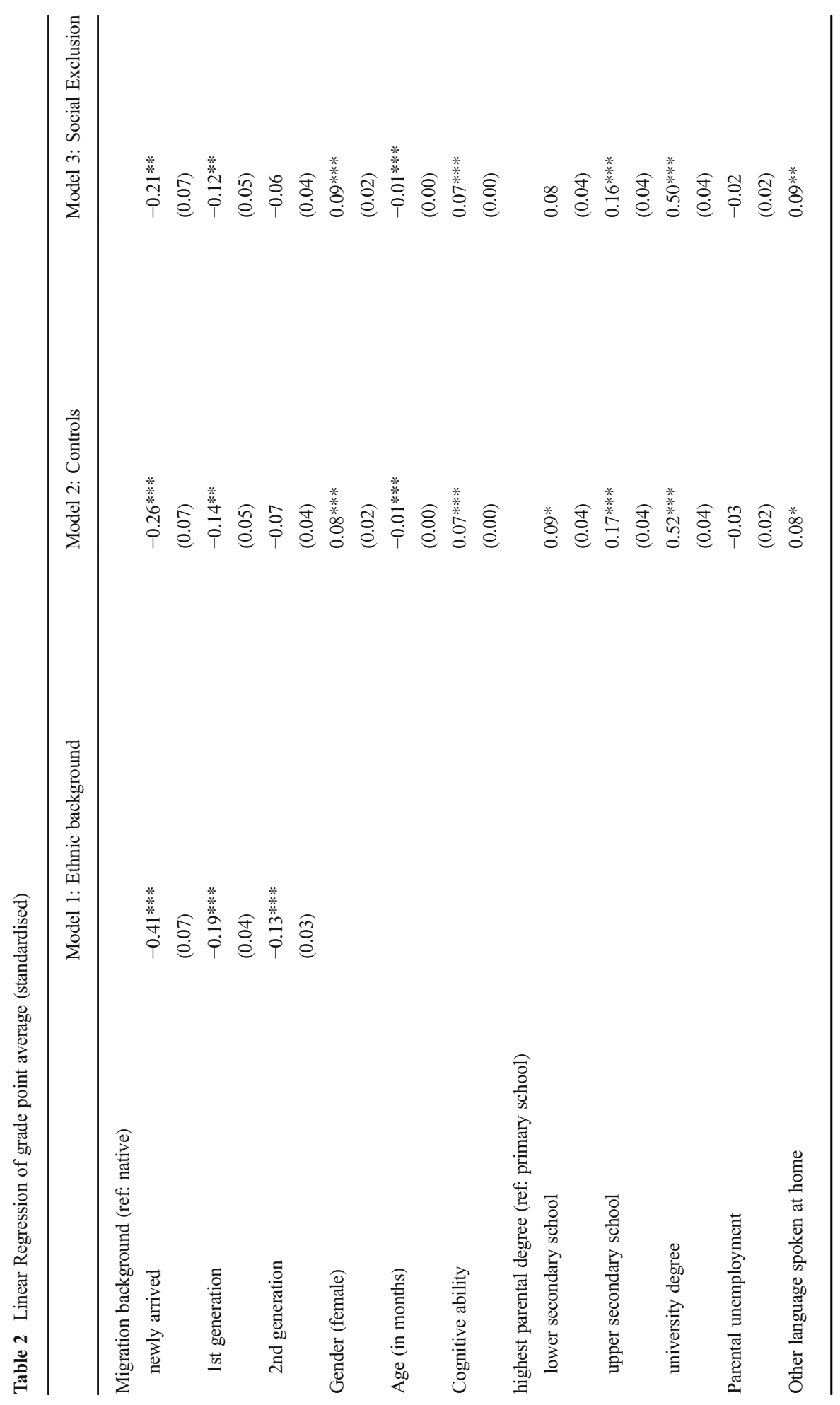




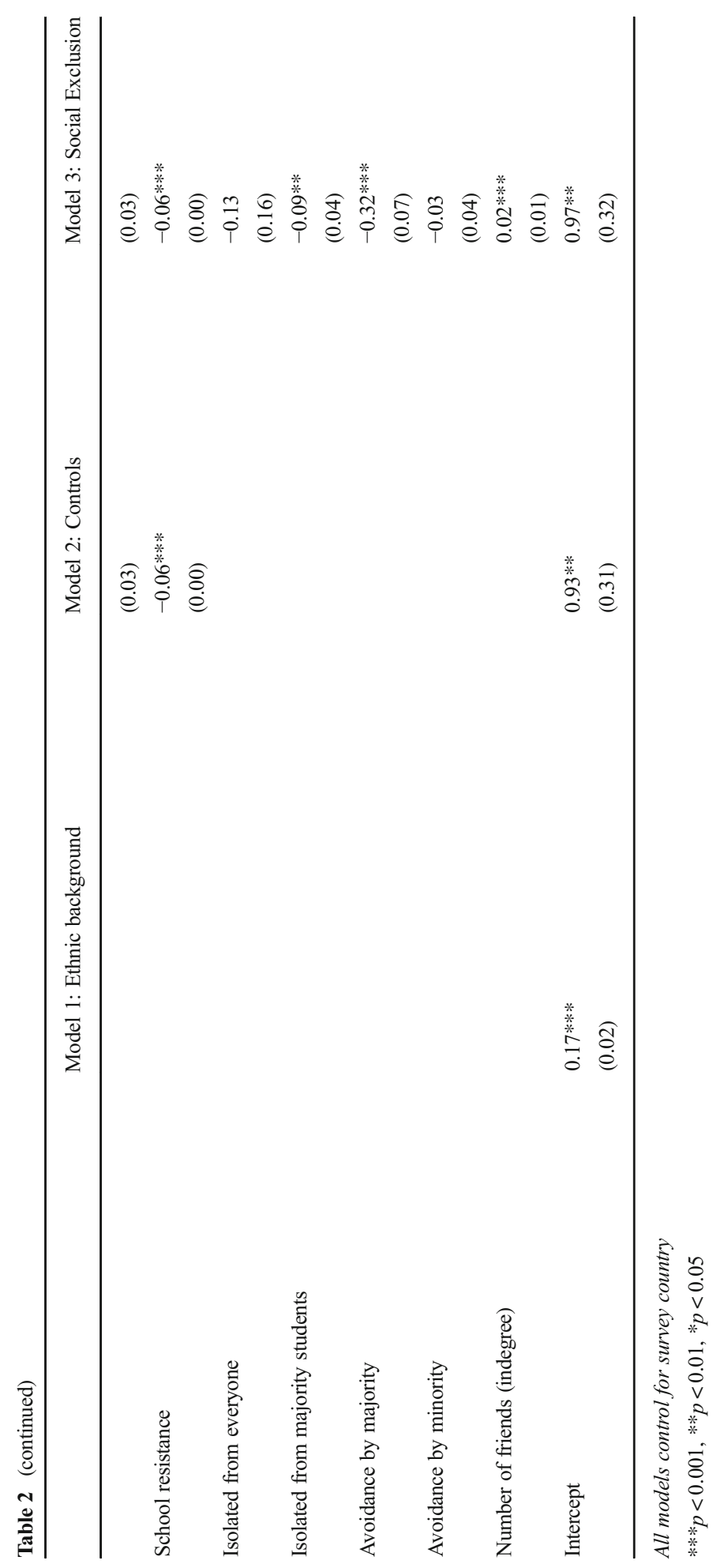


Table 3 Linear Regression of grade point average (standardised)

\begin{tabular}{|c|c|c|c|c|}
\hline & Model 1 & Model 2 & Model 3 & Model 4 \\
\hline Migration background & $\begin{array}{l}-0.05 \\
(0.04)\end{array}$ & $\begin{array}{l}-0.05 \\
(0.04)\end{array}$ & $\begin{array}{l}-0.07 \\
(0.04)\end{array}$ & $\begin{array}{l}-0.05 \\
(0.04)\end{array}$ \\
\hline Gender (female) & $\begin{array}{l}0.13 * * * \\
(0.02)\end{array}$ & $\begin{array}{l}0.13^{* * * *} \\
(0.02)\end{array}$ & $\begin{array}{l}0.13^{* * * *} \\
(0.02)\end{array}$ & $\begin{array}{l}0.13^{* * * *} \\
(0.02)\end{array}$ \\
\hline Age (in months) & $\begin{array}{l}-0.01^{* * * *} \\
(0.00)\end{array}$ & $\begin{array}{l}-0.01^{* * * *} \\
(0.00)\end{array}$ & $\begin{array}{l}-0.01^{* * * *} \\
(0.00)\end{array}$ & $\begin{array}{l}-0.01 * * * \\
(0.00)\end{array}$ \\
\hline Cognitive ability & $\begin{array}{l}0.07 * * * \\
(0.00)\end{array}$ & $\begin{array}{l}0.07 * * * \\
(0.00)\end{array}$ & $\begin{array}{l}0.07 * * * \\
(0.00)\end{array}$ & $\begin{array}{l}0.07^{* * * *} \\
(0.00)\end{array}$ \\
\hline \multicolumn{5}{|l|}{ highest parental degree (ref: primary school) } \\
\hline lower secondary school & $\begin{array}{l}0.11 * \\
(0.04)\end{array}$ & $\begin{array}{l}0.11 * \\
(0.04)\end{array}$ & $\begin{array}{l}0.11 * \\
(0.04)\end{array}$ & $\begin{array}{l}0.11 * \\
(0.04)\end{array}$ \\
\hline upper secondary school & $\begin{array}{l}0.17 * * * \\
(0.04)\end{array}$ & $\begin{array}{l}0.17 * * * \\
(0.04)\end{array}$ & $\begin{array}{l}0.17 * * * \\
(0.04)\end{array}$ & $\begin{array}{l}0.17 * * * \\
(0.04)\end{array}$ \\
\hline university degree & $\begin{array}{l}0.52 * * * \\
(0.04)\end{array}$ & $\begin{array}{l}0.52 * * * \\
(0.04)\end{array}$ & $\begin{array}{l}0.52 * * * \\
(0.04)\end{array}$ & $\begin{array}{l}0.52^{* * *} \\
(0.04)\end{array}$ \\
\hline Parental unemployment & $\begin{array}{l}-0.03 \\
(0.02)\end{array}$ & $\begin{array}{l}-0.03 \\
(0.02)\end{array}$ & $\begin{array}{l}-0.03 \\
(0.02)\end{array}$ & $\begin{array}{l}-0.03 \\
(0.02)\end{array}$ \\
\hline Other language spoken at home & $\begin{array}{l}0.09 * \\
(0.04)\end{array}$ & $\begin{array}{l}0.09 * \\
(0.04)\end{array}$ & $\begin{array}{l}0.09 * \\
(0.04)\end{array}$ & $\begin{array}{l}0.09 * \\
(0.04)\end{array}$ \\
\hline Isolated from everyone & $\begin{array}{l}-0.05 \\
(0.19)\end{array}$ & $\begin{array}{l}-0.05 \\
(0.15)\end{array}$ & $\begin{array}{l}-0.05 \\
(0.15)\end{array}$ & $\begin{array}{l}-0.05 \\
(0.15)\end{array}$ \\
\hline Isolated from majority students & $\begin{array}{l}-0.09 * \\
(0.04)\end{array}$ & $\begin{array}{l}-0.02 \\
(0.11)\end{array}$ & $\begin{array}{l}-0.09 * \\
(0.04)\end{array}$ & $\begin{array}{l}-0.09 * \\
(0.04)\end{array}$ \\
\hline Avoidance by majority & $\begin{array}{l}-0.40 * * * \\
(0.07)\end{array}$ & $\begin{array}{l}-0.40 * * * \\
(0.07)\end{array}$ & $\begin{array}{l}-0.52 * * * \\
(0.10)\end{array}$ & $\begin{array}{l}-0.40^{* * * *} \\
(0.07)\end{array}$ \\
\hline Avoidance by minority & $\begin{array}{l}-0.01 \\
(0.04)\end{array}$ & $\begin{array}{l}-0.01 \\
(0.04)\end{array}$ & $\begin{array}{l}-0.01 \\
(0.04)\end{array}$ & $\begin{array}{l}-0.01 \\
(0.04)\end{array}$ \\
\hline Number of friends (indegree) & $\begin{array}{l}0.02^{* * * *} \\
(0.01)\end{array}$ & $\begin{array}{l}0.02^{* * * *} \\
(0.01)\end{array}$ & $\begin{array}{l}0.02^{* * * *} \\
(0.01)\end{array}$ & $\begin{array}{l}0.02^{* * * *} \\
(0.01)\end{array}$ \\
\hline Isolated from everyone * migration background & $\begin{array}{l}0.01 \\
(0.33)\end{array}$ & & & \\
\hline Isolated from majority students * migration background & & $\begin{array}{l}-0.08 \\
(0.11)\end{array}$ & & \\
\hline Avoidance by majority $*$ migration background & & & $\begin{array}{l}0.22 \\
(0.13)\end{array}$ & \\
\hline Avoidance by minority * migration background & & & & $\begin{array}{l}0.01 \\
(0.12)\end{array}$ \\
\hline intercept & $\begin{array}{l}0.71 * \\
(0.32)\end{array}$ & $\begin{array}{l}0.71 * \\
(0.32)\end{array}$ & $\begin{array}{l}0.73^{*} \\
(0.32)\end{array}$ & $\begin{array}{l}0.72 * \\
(0.32)\end{array}$ \\
\hline
\end{tabular}

All models control for survey country

$* * * \mathrm{p}<0.001, * * \mathrm{p}<0.01, * \mathrm{p}<0.05$ 
suggest that the negative effect of majority students avoiding the individual is weaker for minority students compared to majority students.

\subsection{Robustness Checks}

A critique for the measure of social isolation is that an individual might have all friends outside the classroom. In addition to the full friendship network for each classroom, the CILS4EU data includes information on each individual's five best friends from an ego-network perspective. This means that friends that are nominated in this way are not identified, and not in turn asked to nominate friends as well. That, however, also implies that anyone can be named, whether in the school class or not. Each respondent is then asked to give additional information about each friend, such as their gender, their ethnicity, and whether they are in the same school and class or not. Based on this, the variable for social isolation was redefined in such a way that it only applies to individuals who are socially isolated in the classroom and who do not report friends outside school. Likewise, the variable for social isolation from majority students was redefined in such a way that it only applies to those who have no majority friends inside and outside school. Analyses with both versions of the isolation variable were carried out, and the substantial conclusions remain the same: It does not make a difference if individuals have friends outside school if they are isolated in the classroom. Conceptually, this is a sensible finding, since friends outside the school are not able to help with homework or exam preparations, and might generally be in a different life situation.

As discussed above, social avoidance ties were only counted as such, if the individual did not consider the sender to be their friend. Since there are various reasons for not wanting to sit by someone that they otherwise consider their friend, for example not being able to concentrate on the lessons, analyses were carried out with both versions of the variable. The substantial results are stronger when social avoidance ties coming from friends are excluded. This implies that avoidance ties sent by friends are actually tapping into a different dimension than those from non-friends when it comes to their relationship to grade point average: It is likely that friends, even if they do not want to sit next to the individual, can still be valuable resources of support and advice. While this certainly can be different in other cases, these theoretical arguments strengthen the decision on how to deal with this in the context of this study.

\section{Discussion and Conclusion}

The main finding of this study is that social exclusion is related to lower grade point average, which applies to both majority youths and those with a migration background. Although various concepts of social exclusion were considered, and a tendency for a negative association with GPA was seen throughout the analysis, the only significant results were found for those measures that capture exclusion from the majority students in the classroom: being isolated from majority youths, and being avoided by majority youths. This implies that access to "native social 
resources" matters more, which is in line with theoretical considerations on the beneficial knowledge on manoeuvring the educational system that majority youths are more likely to possess, relative to those with a migration background, as well as to the value of classmates' help with the school work. The possibility of reverse causality cannot be excluded here, so that the association reflects the avoidance of classmates who are underachievers, possibly because of their behaviour, but the analysis manages to control for a number of items indicating school rejection, such as skipping classes and arguing with teachers. The analysis did not show, however, that being socially excluded is worse for migrants, although this test had to be crude to maintain statistical power.

This study set out by asking whether social exclusion can account for some of the disadvantages in grades that children of immigrant origin experience in relation to their peers of majority background. Although the findings show some signs of this, the impression is that this hypothesis was not supported. While exclusion is important for grades, and more children of immigrant origin are socially excluded, the relations are not strong enough to explain the grade difference that was found.

There are limitations to this research. While it is assumed that the mechanism that is investigated here is a general one, the analysis could only include data from three countries, and all of them are European. Ethnic composition of the migrant population varies due to different migration histories of the countries. Since social network data is not a standard feature of large-scale cross-national surveys, future analyses that consider other national contexts depend on the collection of more data of this kind.

Furthermore, this analysis can only point to correlations, while the process linking social exclusion to achievement is likely to start before youths entered secondary school. Collecting and analysing longitudinal data on significant peers and the family from an early age would rectify this limitation. Lastly, more research is needed on the actual mechanism on how social exclusion works, to support and help interpret the initial results that are found in this paper. Next to limited access to social resources, lower mental-wellbeing is another potential pathway by which social exclusion could negatively affect school grades.

However, there are various reasons that render the framing of this study plausible and its findings valuable. While the cross-sectional analysis limits the claims that can be made, there are strong theoretical foundations that build on various strands of previous research, as presented in the literature review. The social dimension is important to include in considerations of educational success, and students who are socially excluded are likely to lack valuable resources, which plays out negatively in their educational success. Most of these combined theoretical implications have not been tested explicitly in the past, due to unavailability of suitable data. Using a large-scale cross-national survey that includes social network data, and can thus accurately measure social dimension of educational success, renders this study particularly valuable.

Acknowledgements I am grateful for support and advice from Jan O. Jonsson, Frank van Tubergen, Carina Mood, Robert Hellpap, Melinda Mills, Anthony Heath, Michael Biggs, Joseph Workman, Felix Tropf, and the Social Networks group in Zürich. 
Open Access This article is distributed under the terms of the Creative Commons Attribution 4.0 International License (http://creativecommons.org/licenses/by/4.0/), which permits unrestricted use, distribution, and reproduction in any medium, provided you give appropriate credit to the original author(s) and the source, provide a link to the Creative Commons license, and indicate if changes were made.

\section{References}

Baumeister, R. F., \& Leary, M. R. (1995). The need to belong: Desire for interpersonal attachments as a fundamental human motivation. Psychological Bulletin, 117(3), 497-529.

Block, P. (2015). Reciprocity, transitivity, and the mysterious three-cycle. Social Networks, 40, $163-173$. https://doi.org/10.1016/j.socnet.2014.10.005.

Boda, Z., \& Néray, B. (2015). Inter-ethnic friendship and negative ties in secondary school. Social Networks, 43, 57-72. https://doi.org/10.1016/j.socnet.2015.03.004.

Brown, B. B. (2004). Handbook of adolescent psychology (2nd ed.pp. 363-394). Hoboken: Wiley.

CILS4EU (2014). Children of Immigrants Longitudinal Survey in Four European Countries. Technical Report. Wave 1-2010/2011, v1.1.0. Mannheim: Mannheim University.

Dollmann, J., Jacob, K., \& Kalter, F. (2014). Examining the Diversity of Youth in Europe (Vol. 156, pp. 1-45). Mannheim: Mannheim Center for European Social Research.

Erikson, R., \& Jonsson, J. O. (1996). Can education be equalized? Boulder: Westview Press.

Geven, S., Jonsson, J. O., \& Tubergen, F. (2017). Gender differences in resistance to schooling: The role of dynamic peer-influence and selection processes. Journal of Youth and Adolescence, 46, 2421-2445. https://doi.org/10.1007/s10964-017-0696-2.

Heath, A. F., \& Brinbaum, Y. (2014). Unequal attainments. USA: Oxford University Press.

Heath, A. F., Rothon, C., \& Kilpi, E. (2008). The second generation in Western Europe: Education, unemployment, and occupational attainment. Annual Review of Sociology, 34(1), 211-235. https://doi. org/10.1146/annurev.soc.34.040507.134728.

Hjalmarsson, S., \& Mood, C. (2015). Do poorer youth have fewer friends? The role of household and child economic resources in adolescent school-class friendships. Children and Youth Services Review, 57, 201211. https://doi.org/10.1016/j.childyouth.2015.08.013.

Jencks, C., Crouse, J., \& Mueser, P. (1983). The Wisconsin model of status attainment. Sociology of Education, 56(1), 3. https://doi.org/10.2307/2112300.

Kalter, F., Heath, A., Hewstone, M., Jonsson, J. O., Kalmijn, M., Kogan, I., \& Tubergen, F. V. (2014). Children of Immigrants Longitudinal Survey in Four European Countries (CILS4EU). https://doi. org/10.4232/cils4eu.5353.1.1.0

Kalter, F., Heath, A., Hewstone, M., Jonsson, J. O., Kalmijn, M., Kogan, I., \& Tubergen, F. V. (2015). Children of immigrants longitudinal survey in four European countries (CILS4EU). https://oi. org/10.4232/cils4eu.5353.2.1.0.

Lin, N. (1999). Building a network theory of social capital. Connections, 22(1), 28-51.

Lin, N. (2000). Inequality in social capital. Contemporary Sociology, 29(6), 785-795. https://doi.org/10.2307 /2654086?ref=search-gateway:ccd9fle37227520342b19f47e4b51e69.

McDougall, P., \& Vaillancourt, T. (2015). Long-term adult outcomes of peer victimization in childhood and adolescence: Pathways to adjustment and maladjustment. American Psychologist, 70(4), 300-310. https://doi.org/10.1037/a0039174.

McPherson, M., Smith-Lovin, L., \& Cook, J. M. (2001). Birds of a feather: Homophily in social networks. Annual Review of Sociology, 27, 415-444. https://doi.org/10.2307/2678628?ref=search-gateway:e197b0 dab973a7aab7252ea2b29dacbb.

Nakamoto, J., \& Schwartz, D. (2010). Is peer victimization associated with academic achievement? A metaanalytic review. Social Development, 19(2), 221-242. https://doi.org/10.1111/j.1467-9507.2009.00539.x.

Osterman, K. F. (2000). Students' need for belonging in the school community. Review of Educational Research, 70, 323-367.

Plenty, S., \& Jonsson, J. O. (2017). Social exclusion among peers: The role of immigrant status and classroom immigrant density. Journal of Youth and Adolescence, 46(6), 1275-1288. https://doi.org/10.1007/s10964016-0564-5.

Stock, J. H., \& Watson, M. W. (2008). Heteroskedasticity-robust standard errors for fixed effects panel data regression. Econometrica, 76(1), 155-174. https://doi.org/10.2307/4502057?ref=search-gateway:86b95 a3956dc578feb7f789cf75c6187. 
van Tubergen, F., \& van de Werfhorst, H. (2007). Postimmigration investments in education: A study of immigrants in the Netherlands. Demography, 44(4), 883-898. https://doi.org/10.1353/dem.2007.0046.

Vervoort, M. H. M., Scholte, R. H. J., \& Overbeek, G. (2008). Bullying and victimization among adolescents: The role of ethnicity and ethnic composition of school class. Journal of Youth and Adolescence, 39(1), 111. https://doi.org/10.1007/s10964-008-9355-y.

Vörös, A., \& Snijders, T. A. B. (2017). Cluster analysis of multiplex networks: Defining composite network measures. Social Networks, 49, 93-112. https://doi.org/10.1016/j.socnet.2017.01.002.

Wright, J. C., Giammarino, M., \& Parad, H. W. (1986). Social status in small groups: Individual-group similarity and the social "misfit.". Journal of Personality and Social Psychology, 50(3), 523-536. https://doi.org/10.1037/0022-3514.50.3.523.

Youniss, J., \& Smollar, J. (1985). Adolescent relations with mothers, fathers, and friends. Chicago: University of Chicago Press. 